\title{
Changing the conversation about prostate cancer among African Americans: results of formative research
}

Ricardo J. Wray ${ }^{\mathrm{a} *}$, Stephanie McClure ${ }^{\mathrm{b}}$, Santosh Vijaykumar ${ }^{\mathrm{a}}$, Christopher Smith ${ }^{\mathrm{c}}$, Andrae Ivy ${ }^{\mathrm{d}}$, Keri Jupka ${ }^{\mathrm{a}}$, \& Richard Hess

${ }^{a}$ Saint Louis University School of Public Health, Community Health, St. Louis, MO, USA; ${ }^{b}$ Anthropology, Case Western Reserve University, Cleveland, OH, USA; ${ }^{c}$ Public Health Prevention Service Fellowship, Centers for Disease Control and Prevention, Atlanta, GA, USA; ${ }^{d}$ Northrup Grumman Contractor, Centers for Disease Control and Prevention, Atlanta, GA, USA; ${ }^{e}$ Surgery-Urology, Saint Louis University Medical Center, St. Louis, MO, USA

Objectives. To understand obstacles to and opportunities for improving prostate cancer communication to and within African American communities.

Design. Researchers conducted interviews with 19 community leaders and five focus groups with healthy men and survivors. The team also conducted process evaluations of two outreach projects in which survivors spoke to African American men about prostate cancer and screening.

Results. Three levels of obstacles to prostate cancer screening and treatment were identified. Individual-level obstacles included limited knowledge about the condition, about prevention and treatment, and fear of cancer. Socio-cultural barriers included distrust of the medical system, lack of a provider for routine and preventive care, reluctance to talk about cancer, and aversion to aspects of screening. Institutional deficits included the scarcity of educational efforts targeting prostate cancer. Outreach project evaluations suggested that survivors can be effective in building prostate cancer knowledge, promoting positive attitudes toward screening, and fostering conversations about prostate cancer. Educational efforts included little information about screening risks and decisionmaking however.

Conclusions. The findings suggest that most potent interventions may combine survivor-led education with mass media and institution-based outreach. Such comprehensive programs could shift social norms that inhibit conversation and foster fear, leading in turn to more informed decisions and better treatment outcomes.

Keywords: prostate cancer; communication; decision-making; African Americans

\section{Introduction}

Prostate cancer is the most frequently diagnosed cancer, and the third most common cause of cancer deaths among American men, claiming an estimated 28,660 lives in 2008 (ACS 2008). Disparities specific to prostate cancer are marked. Although mortality due to prostate cancer has been declining among both African American and White men since the early 1990s, it remains more than two times greater among

*Corresponding author. Email: wray@slu.edu 
African Americans than Whites (68.1 vs. 27.7 per 100,000 from 1998 to 2002 (ACS 2006)). Disparities in incidence and mortality are explained in part by inequities in access to treatment and in quality of medical care faced by African Americans (Shavers and Brown 2002, Ward et al. 2004). African American men are less likely to be screened for prostate cancer than White men (Shavers and Brown 2002, Fowke et al. 2005), and so are more likely to have advanced disease when diagnosed with prostate cancer (deVere White et al. 1998, Ries et al. 2000). Differences in socioeconomic status (SES) and comorbid conditions explain only a small part of the differences in screening rates (Gilligan et al. 2004). Previous research has reported relatively low levels of knowledge about prostate cancer among African American men (Demark-Wahnefried et al. 1995). The combination of low knowledge of the disease, advanced-stage diagnosis, and disproportionately high mortality underscores the identification of African Americans as a priority group for prostate cancer prevention efforts (Powell et al. 1997).

Risk factors for prostate cancer include African American ethnicity, older age and family history (ACS 2008). No proven means for primary prevention of prostate cancer currently exist, though chemoprevention strategies and diet regimens that are low in fat, calcium and alcohol show promise and are under study (ACS 2006). Many view secondary prevention (i.e., screening) as the only available strategy to reasonably elicit a substantial reduction in prostate cancer mortality (Barry 2001). However, the subject of prostate cancer screening remains contentious, as there is no clear evidence that it decreases mortality (Barry 2001).

Prostate cancer is unique in that most men who have it die of other conditions. More than $90 \%$ of men diagnosed have a local or regional case of prostate cancer. With or without treatment, the five-year survival rate for these men is almost $100 \%$. For the $10 \%$ of men diagnosed with metastatic cancer, the five-year survival rate is $33.3 \%$ (ACS 2007).

Two kinds of screening are useful for the detection of increased risk for prostate cancer. The digital rectal exam (DRE) involves a clinician inserting a lubricated, gloved finger into the distal of the rectum to palpate for nodules or other anatomical abnormalities of the prostate gland. The prostate-specific antigen (PSA) test measures the level of a glycoprotein produced almost exclusively by the prostate that may be found in an increased amount in the blood of men who have prostate cancer. The level of serum PSA may also be high in men who have other noncancerous prostate conditions (National Cancer Institute 2007).

The argument against screening stems from a high false-positive rate associated with PSA testing, the substantial morbidity associated with prostate cancer treatments and the concern that much of the cancer discovered as a result of screening may not be destined to spread or cause the patient any problems (Brawley 1997). Opponents of prostate cancer screening argue that it may direct men to unnecessary and/or unbeneficial prostate surgery and radiotherapy with notably high risks of serious side effects including impotence and incontinence (Brawley 1997).

In the absence of data showing a mortality or quality-of-life benefit, patients considering screening must make a difficult decision. The decision involves balancing the hypothetical mortality benefit that may result from earlier detection against the risks associated with therapy. Most major medical organizations that issue preventive service guidelines have chosen not to endorse routine prostate cancer screening (USPSTF 1996, Ferrini and Woolf 1998), and recommend instead that 
patients make an informed decision about screening after weighing the risks and benefits with their physician (Chan 2001, Chu et al. 2003).

The argument for prostate cancer screening thus rests on the rationale that screening can be expected to save lives because survival correlates with disease stage at the time of diagnosis. Recent research has bolstered this argument, showing a survival benefit for men actively treated compared to watchful waiting (Wong et al. 2006). PSA and DRE screening clearly result in greater percentages of men diagnosed with early-stage disease. This logic has proven persuasive to patients and physicians alike as prostate cancer screening is now common. According to the 2004 Behavioral Risk Factor Surveillance Survey (BRFSS), 52.1\% of men aged 40 and over had a PSA test within the previous two years (CDC 2006). Given the professional ambivalence about the practice, such high screening rates underscore the need for research about screening decision-making.

\section{Determinants of prostate cancer screening}

Studies of the correlates and predictors of prostate cancer screening have identified socio-demographic factors associated with attitudes toward and participation in screening, including ethnicity (Steele et al. 2000), higher educational achievement (Myers et al. 2000, Agho and Lewis 2001, Ashford et al. 2001), older age (Steele et al. 2000, Agho and Lewis 2001), and physician support of prostate cancer screening (Myers et al. 2000, Steele et al. 2000). Several studies found that health beliefs about prostate cancer, screening and treatment were associated with screening rates (Tingen et al. 1998, Myers et al. 2000). Whether increased knowledge about prostate cancer leads to higher screening rates remains unclear (Steele et al. 2000, Agho and Lewis 2001, Ashford et al. 2001). Attitudes toward the risk of prostate cancer and the benefits of screening are more predictive of behavior than is knowledge about prostate cancer (Ashford et al. 2001). Whether ethnic differences in such attitudes exist or contribute to health disparities has not been established (Kressin et al. 2002).

Long-standing and well-documented issues exist concerning unequal treatment and access to care experienced by African Americans throughout the history of the USA (Dressler 1993). These persistent inequities have resulted in generally lower levels of trust in the health care system among African Americans (Gamble 1993). Financial barriers, lower general and health literacy, and the considerable challenges of navigating the health care system compound the difficulty of seeking and receiving appropriate, timely care (Dressler 1993).

Outreach programs educating African American men about prostate cancer and advocating prostate cancer screening have successfully recruited substantial numbers of men for screening (Powell et al. 1997, Weinrich et al. 1998a, Weinrich et al. 1998b, Abernethy et al. 2005). A variety of educational tools in the form of brochures, pamphlets, and videos have been disseminated and proved to be effective decisionmaking aids for men, increasing knowledge and awareness (Partin et al. 2004, Hewitson and Austoker 2005). A number of programmatic elements appear to help such screening initiatives succeed, including collaborating with work sites, churches, and housing projects and engaging with men through peer educators and client navigators (Powell et al. 1997). African American participants in outreach programs have been found to have less knowledge about prostate cancer risk factors and early symptoms than Whites but this difference resolves following educational 
interventions (Demark-Wahnefried et al. 1995). Several experimental research studies have explored informed decision-making for prostate cancer screening. Lower screening rates have resulted among men in the informed decision-making study arms, compared to those in the screening promotion arms. This result can be construed as an indication of success of the decision-making intervention, given a greater emphasis on screening risks and independent decisions. The level of understanding of risks and decision-making satisfaction are not reported however (Volk et al. 1999). Other research has shown that involvement by patients in treatment decisions can result in better psychological adjustment and mood following treatment (Deadman et al. 2001).

Given disproportionately high mortality from prostate cancer, perceived low levels of within-group knowledge about prostate cancer, and socio-cultural factors affecting African Americans' screening and treatment, the literature identifies a need for sensitive and penetrating research to understand the complex circumstances surrounding prostate cancer communication in African American communities. The present paper reports on two sets of studies conducted between 2003 and 2006 in St. Louis, MO, that sought to understand issues related to prostate cancer communication with and among African American men from the perspective of the men themselves, and organizations that serve them. The multiple methods used in the studies offer results that contribute to potential strategies to support screening decision-making and enhance prostate cancer care among African Americans.

\section{Methods}

From 2003 to 2005, the study team carried out a community-based participatory needs assessment that sought to understand opportunities and challenges related to prostate cancer communication. Key informant interviews (KIs) with community leaders and focus groups with healthy men and survivors were the means of assessment. In 2005 and 2006, the team conducted process evaluations of two outreach projects that employed survivors and peer educators to promote improved knowledge and screening practices in community settings. The process evaluations used a multi-method approach including participant observations and in-depth interviews with peer educators and discussion participants. Institutional Review Board approval was received for each phase of the research. Figure 1 depicts in schematic form the study design, timeline, and data sources for the prostate cancer needs assessment and process evaluations.

\section{Key informant interviews (KIs) with community leaders (2003-2004)}

Community leaders were recruited as key informants through existing contacts with colleagues in the community. The informants represented multiple perspectives, including those of community development and health organizations, elected officials, reporters, business people and survivors. A semi-structured interview guide followed a conceptual framework (presented in Table 1) based on multiple level determinants and consistent with the Social Ecological Model (Stokols 1992), namely, individual-level barriers (e.g., psychosocial and demographic factors) and social-structural barriers (e.g., institutional and community factors). Questioning included how to address identified barriers. 

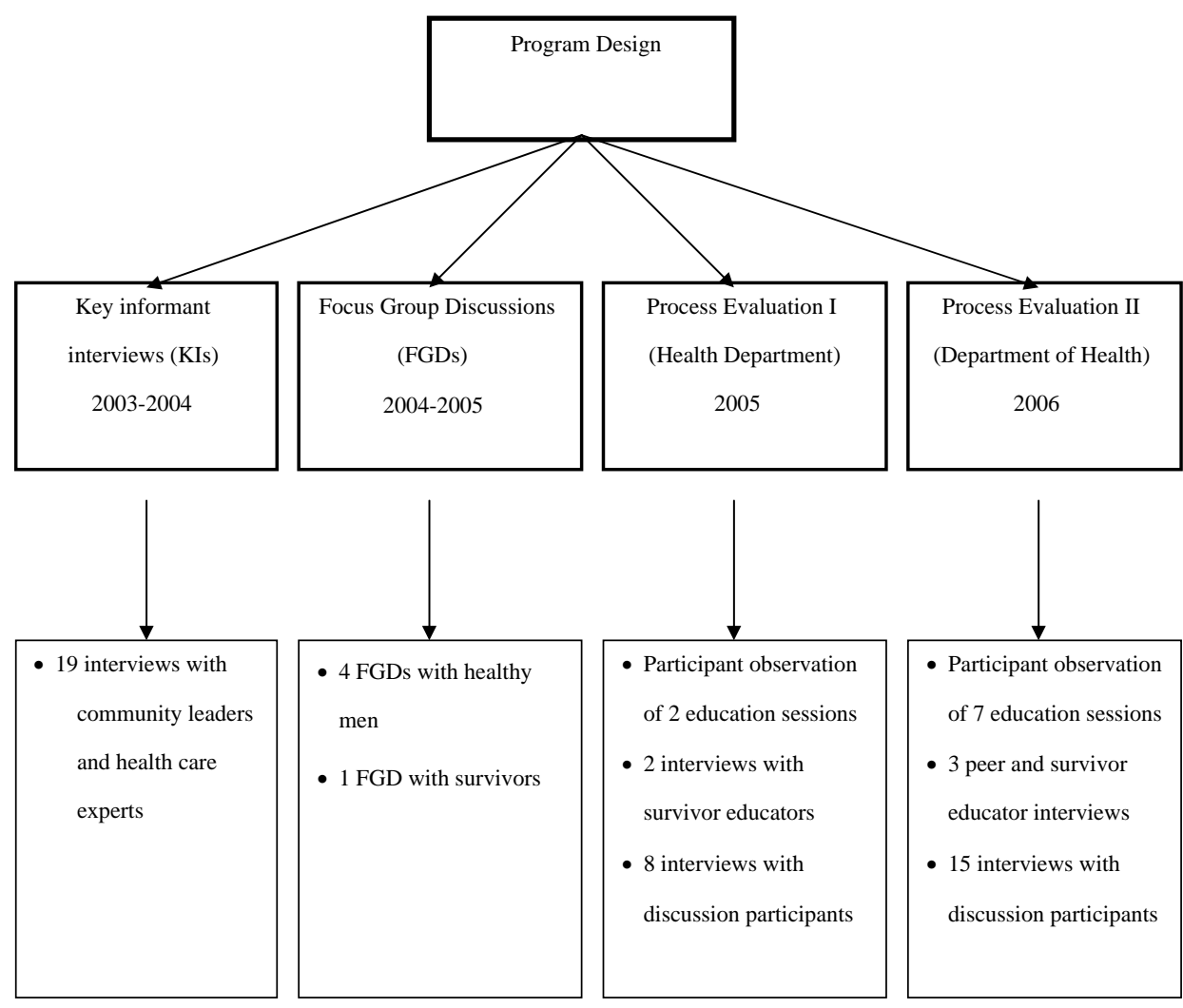

Figure 1. Prostate cancer needs assessment and process evaluations: schematic of study design, timeline, and data sources.

Trained interviewers conducted the interviews, and one or two note-takers took notes. Interviews were also audiotaped. Interview notes were coded and analyzed using a coding guide based on the domains that shaped the interviews. At the same time new and unanticipated socio-cultural constructs emerged. Two analysts coded the notes separately, then discussed their findings and reached consensus on results, interpretation and report writing (Miles and Huberman 1994). The final report on the interviews was distributed to the key informants for their information and feedback.

\section{Focus groups with healthy men and prostate cancer survivors (2004-2005)}

Five focus groups were carried out - four with healthy men and one with survivors. Community partners were invited to convene groups of men. The discussion guide followed the same multi-level framework as the KIs (see Table 1). An experienced moderator conducted the focus groups, which were audiotaped and documented by one or two note-takers. Each focus group was followed by a short presentation and question and answer session led by a content expert on prostate cancer. Verbal and non-verbal notes, summary reports prepared immediately after the groups, and 
Table 1. Conceptual framework for key informant interviews and focus group discussion guides.

\begin{tabular}{|c|c|c|}
\hline Key informant interviews & Healthy men focus groups & $\begin{array}{l}\text { Prostate cancer survivor } \\
\text { focus group }\end{array}$ \\
\hline \multicolumn{3}{|c|}{ Individual-level factors } \\
\hline $\begin{array}{l}\text { Prostate cancer knowledge } \\
\text { barriers to care among } \\
\text { African American men }\end{array}$ & $\begin{array}{l}\text { Knowledge of prostate, } \\
\text { prostate cancer, risk factors, } \\
\text { treatment }\end{array}$ & $\begin{array}{l}\text { Experience with diagnosis, } \\
\text { treatment, and survivorship }\end{array}$ \\
\hline $\begin{array}{l}\text { Barriers to prostate cancer } \\
\text { care among African } \\
\text { American men }\end{array}$ & Barriers to care & $\begin{array}{l}\text { Treatment decision-making } \\
\text { process; sources of support }\end{array}$ \\
\hline $\begin{array}{l}\text { Screening knowledge, beliefs, } \\
\text { attitudes and practices } \\
\text { among African American } \\
\text { men }\end{array}$ & $\begin{array}{l}\text { Knowledge of prostate cancer } \\
\text { screening guidelines; } \\
\text { screening decision making } \\
\text { and practices }\end{array}$ & $\begin{array}{l}\text { Screening decision making } \\
\text { and practices }\end{array}$ \\
\hline No corresponding topic & $\begin{array}{l}\text { Healthcare-seeking practices: } \\
\text { routines and concerns; } \\
\text { relationships with providers }\end{array}$ & $\begin{array}{l}\text { Experiences with providers } \\
\text { while in treatment }\end{array}$ \\
\hline \multicolumn{3}{|c|}{ Social-structural } \\
\hline $\begin{array}{l}\text { Barriers to care specific to } \\
\text { African American men, } \\
\text { including effects of } \\
\text { provider race and gender }\end{array}$ & $\begin{array}{l}\text { Issues around barriers to care } \\
\text { specific to men, or African } \\
\text { American men }\end{array}$ & $\begin{array}{l}\text { Barriers to treatment and } \\
\text { quality care }\end{array}$ \\
\hline $\begin{array}{l}\text { Institutional characteristics } \\
\text { and practices bearing on } \\
\text { quality of care }\end{array}$ & $\begin{array}{l}\text { Access to medical care; } \\
\text { relationship with health care } \\
\text { institutions }\end{array}$ & $\begin{array}{l}\text { Experiences with health care } \\
\text { institutions while in } \\
\text { treatment }\end{array}$ \\
\hline Community factors bearing & No corresponding topic & No corresponding topic \\
\hline \multicolumn{3}{|c|}{ Potential solutions } \\
\hline $\begin{array}{l}\text { Strategies for individual } \\
\text { behavior change }\end{array}$ & No corresponding topic & $\begin{array}{l}\text { Strategies to increase } \\
\text { awareness }\end{array}$ \\
\hline $\begin{array}{l}\text { Institutional strategies to } \\
\text { improve care for African } \\
\text { American men }\end{array}$ & Institutional strategies & Institutional strategies \\
\hline $\begin{array}{l}\text { Strategies for dissemination } \\
\text { of health information }\end{array}$ & $\begin{array}{l}\text { Health information seeking } \\
\text { practices }\end{array}$ & $\begin{array}{l}\text { Talking about their } \\
\text { experience }\end{array}$ \\
\hline $\begin{array}{l}\text { Strategies for community } \\
\text { mobilization }\end{array}$ & $\begin{array}{l}\text { Venues for community } \\
\text { mobilization }\end{array}$ & No corresponding topic \\
\hline $\begin{array}{l}\text { Recommendations for media } \\
\text { channels and sources }\end{array}$ & $\begin{array}{l}\text { Preferred sources for health } \\
\text { information: interpersonal, } \\
\text { providers, media }\end{array}$ & $\begin{array}{l}\text { Sources of information: } \\
\text { interpersonal, providers, } \\
\text { media }\end{array}$ \\
\hline $\begin{array}{l}\text { Recommendations for } \\
\text { communication strategies } \\
\text { and messages }\end{array}$ & Potential messages & Potential messages \\
\hline
\end{tabular}


audiotapes were used to code and analyze focus group data, following the same consensus-based approach as the interviews.

\section{Process evaluations of two prostate cancer outreach projects (2005-2006)}

The study team was hired through subcontracts to evaluate two prostate cancer outreach initiatives undertaken by a local municipal health department and a health ministry based in a local church. Peer and survivor educators were given a stipend or volunteered to educate community members about prostate cancer and screening. Educational sessions were conducted formally at local organizations (e.g., fraternity graduate chapters or churches), or informally at unplanned sessions with men in restaurants or other settings.

In the evaluations, the study team addressed two research objectives: (1) documenting what happened in the intervention; and (2) acquiring preliminary data regarding intervention effectiveness. The methods - participant observation and in-depth interviews with peer educators and discussion participants - introduced independent and complementary data.

Study team members attended select outreach education sessions as participant observers. At the end of each session, the peer and survivor educators asked discussion participants if they were willing to be contacted for a follow-up interview, and collected phone numbers of those assenting. The study team subsequently conducted telephone interviews about the sessions with the peer and survivor educators and willing discussion participants. Measurement for both methods addressed the tone and content of the discussion, receptivity of participants, the characteristics of the setting; and perceived effects of the intervention on knowledge, attitudes, screening intention and subsequent conversations about the topic with friends and family (see Table 2). Coding, analysis and reporting of observation and interview notes followed the consensus-based approach of the needs assessment.

\section{Triangulation of findings}

Needs assessment and process evaluation results were triangulated using matrices to identify thematic similarities and differences between studies. This synthesis yielded individual, socio-cultural and institutional factors limiting knowledge and action, and potential ways to improve prostate cancer communication for African American men. The process evaluation results are primarily reported within the domain of potential solutions. Statements from participants interspersed in the findings below are excerpted from notes and are not verbatim statements.

\section{Findings}

\section{Description of study participants}

A total of 51 men and women participated in the needs assessment as key informants (19) or focus group discussants (32). An additional 28 men were interviewed for the process evaluations, for a total sample of 79 respondents contributing to the findings reported here. The 19 key informants comprised 17 men and two women, and 18 African Americans and one White. Key informants represented the following professions: health care professionals (4), clergy (2), elected officials (2), journalists 
Table 2. Conceptual framework for the process evaluations.

\begin{tabular}{|c|c|c|c|}
\hline & $\begin{array}{c}\text { Participant } \\
\text { observations }\end{array}$ & $\begin{array}{l}\text { Peer educator } \\
\text { interviews }\end{array}$ & $\begin{array}{l}\text { Follow-up interviews } \\
\text { with participant }\end{array}$ \\
\hline $\begin{array}{c}\text { What happens } \\
\text { during the } \\
\text { discussions? }\end{array}$ & $\begin{array}{l}\text { Objective measures } \\
\text { - Logistics } \\
\text { - Topics covered } \\
\text { - Proportion of time on } \\
\text { topic } \\
\text { - Traffic/log Subjective } \\
\text { measures } \\
\text { - Tone } \\
\text { - Interactivity } \\
\text { - Dynamics } \\
\text { - Seems interested }\end{array}$ & $\begin{array}{l}\text { - Assessment of } \\
\text { context and } \\
\text { environment } \\
\text { - Problems faced } \\
\text { - Strategies for } \\
\text { introducing topic } \\
\text { - Characteristics of } \\
\text { group } \\
\text { - Comfort level }\end{array}$ & $\begin{array}{l}\text { - Credibility of peer } \\
\text { interviewer } \\
\text { - Perception of session } \\
\text { - Comfort level } \\
\text { - Family history of } \\
\text { cancer }\end{array}$ \\
\hline $\begin{array}{l}\text { Perceived effects } \\
\text { on outcomes }\end{array}$ & $\begin{array}{l}\text { - Verbal indications of } \\
\text { new knowledge } \\
\text { - Interests in learning } \\
\text { more/questions } \\
\text { - Stated intention to } \\
\text { screen }\end{array}$ & $\begin{array}{l}\text { - Perceived effects on } \\
\text { knowledge, beliefs, } \\
\text { intentions } \\
\text { - Evidence for effects } \\
\text { (non-verbal, } \\
\text { attentiveness, } \\
\text { questions, etc.) }\end{array}$ & $\begin{array}{l}\text { - Did you learn new } \\
\text { knowledge } \\
\text { - Previous views } \\
\text { changed } \\
\text { - Discussed session } \\
\text { with family and } \\
\text { friends }\end{array}$ \\
\hline
\end{tabular}

(2), businessmen (4), academics (1), and community organizers (4). In addition, three of the key informants were prostate cancer survivors. Twenty-eight African American men participated in the focus groups of healthy men, and four participated in the survivor focus group. The cancer status of the men was self-reported and classified men as healthy (i.e., never diagnosed with cancer) or as a prostate cancer survivor who had been diagnosed and had completed treatment. For the process evaluations, participant observers attended nine discussion sessions with 85 participants, interviewed five peer educators (including four survivors), and interviewed 23 discussion participants by telephone.

Demographics of the focus group and outreach session participants were not measured systematically, but were estimated by participant observers and notetakers, and are reported in Table 3 . The 32 focus group participants ranged in age from 40 to 80 , as did the 23 participants in the sessions led by the health department. Sixty-two men participated in the discussion sessions led by the health ministry; several of these discussion sessions included men who were in their $20 \mathrm{~s}$ and $30 \mathrm{~s}$, but most men were also in the 40-80-year-old age range. The SES and education levels of the men varied between groups.

\section{Individual and socio-cultural factors}

Key informants indicated that African American men with low SES and poor education were less likely to get screened or treated for prostate cancer. At the same time, however, participants said that professional men are also unlikely to maintain an appropriate health care routine and seek cancer screening. They attributed this to 
Table 3. Venue, number and characteristics of focus group and outreach session participants.

\begin{tabular}{|c|c|c|c|c|c|}
\hline Group or session & Venue & $\begin{array}{l}\text { Number of } \\
\text { participants }\end{array}$ & Age range & Education $^{\mathrm{a}}$ & $\mathrm{SES}^{\mathrm{b}}$ \\
\hline \multicolumn{6}{|l|}{ Focus groups } \\
\hline Healthy men group 1 & Church meeting hall & 12 & $40-80$ & $\begin{array}{l}\text { Mixed: Middle/ } \\
\text { high }\end{array}$ & Mixed: Middle/high \\
\hline Healthy men group 2 & Community center & 8 & $50-75$ & Low & Low \\
\hline Healthy men group 3 & $\begin{array}{l}\text { University meeting } \\
\text { room }\end{array}$ & 4 & $40-75$ & Middle & Mixed: Middle/high \\
\hline Healthy men group 4 & Community center & 4 & $60-80$ & Low & Low \\
\hline Survivors group 1 & $\begin{array}{l}\text { University meeting } \\
\text { room }\end{array}$ & 4 & $40-60$ & Mixed: Low/middle & Mixed: Low/middle \\
\hline \multicolumn{6}{|c|}{ Municipal health department outreach program } \\
\hline Session 1 & Fraternal organization & 10 & $40-75$ & Mixed: Low/middle & Mixed: Low/middle \\
\hline Session 2 & Restaurant & 13 & $55-70$ & Mixed: Low/middle & Mixed: Low/middle \\
\hline \multicolumn{6}{|c|}{ Church-based health ministry outreach program } \\
\hline Session 1 & Church meeting hall & 8 & $50-70$ & Low & Low \\
\hline Session 2 & Church meeting hall & 10 & $20-50$ & Low & Low \\
\hline Session 3 & Church meeting hall & 5 & $50-60$ & Middle & Middle \\
\hline Session 4 & Community center & 9 & $20-30$ & Low & Mixed: Low/Middle \\
\hline Session 5 & Church meeting hall & 11 & $40-70$ & Middle & Middle \\
\hline Session 6 & Community center & 8 & $40-60$ & Low & Low \\
\hline Session 7 & Church meeting hall & 11 & $30-70$ & Low & Low \\
\hline
\end{tabular}

${ }^{a}$ Definitions of education categories: Low, high school or less; Middle, bachelors degree or some college; High, graduate studies.

${ }^{\mathrm{b}}$ Definitions of SES categories: Low, <\$25,000; Middle, \$25,000-\$50,000; High, > $\$ 50,000$. 
the lack of routine preventive care and the tendency among African American men to seek medical care only upon appearance of symptoms. 'I am surprised at the number of professional men - doctors and lawyers - that have prostate issues, but don't seek treatment' (Key informant).

Key informant interview and focus group participants reported low levels of knowledge among most African American men about prostate cancer, risk factors, and screening and treatment options. In addition, what knowledge there is about prostate cancer treatment invokes fear and discomfort. 'It affects your manhood to say something is wrong with your prostate, this also says that something is wrong with your sexual function. Men fear that they will always be labeled as being sick after the surgery' (Key informant). The threat of sexual dysfunction posed by prostate cancer leads to a heightened desire to distance oneself from even the possibility of illness. 'As long as I don't know I have it, I don't have it' (Healthy men focus group participant).

Striking and unanticipated findings emerged in the area of social norms. Interview and focus group participants commented on a common reluctance to discuss the topic of prostate cancer with family and friends. 'It is a taboo subject for African American men. It is only talked about if someone had it or has it' (Key informant). Key informants noted a common lack of routine preventive care among African American men: 'African American men have a history of not going to the doctor' (Key informant). Participants also commented upon a tendency to deny the need for health care even if they were sick. Another concern was that aspects of prostate cancer screening carry a sense of stigma among African American men: 'A lot of African American men are offended by the DRE' (Key informant). Interview and focus group participants reported a normative distrust of health care providers and the health care system. 'Lack of trust is passed down from older men to younger generations' (Healthy men focus group participant).

\section{Social-structural barriers}

Both needs assessment and evaluation participants remarked upon several structural barriers to prostate cancer care, noting, for example, that unemployment and lack of insurance were important barriers to screening. Interview and focus group participants commented on continuing perceptions of discrimination against African Americans by health care institutions, and continued distrust in return. They indicated that the scarcity of African American providers and community-based services discouraged African American men from seeking prostate cancer care. Participants stated that outreach on prostate cancer was inadequate, with few programs and services in place to inform African American men about prostate cancer. 'We haven't done a good job getting the word out about prostate cancer' (Key informant). Participants mentioned a few prostate cancer awareness and screening provision activities underway from service providers, churches, and community organizations, but these activities were typically sporadic and discrete to specific community organizations (e.g., annual screening events). In addition, screening services were viewed as scarce and inconvenient.

Key informants suggested that little leadership on the topic exists in African American communities. 'Community gatekeepers need to be more responsive ... It would be helpful just to get basic information to the community. Leaders don't get 
that part of the puzzle' (Key informant). A few informants indicated that ethnic tensions and distrust in St. Louis can get in the way of efforts to improve services.

\section{Potential solutions}

A variety of innovative, concrete and urgent recommendations emerged from the community-based research. Key informants and focus group participants highlighted the need for multi-faceted initiatives that include health institutions working in partnership with media and community organizations, worksites, schools and churches. 'This is like the issue of child abuse: no single agency can or should ever assume sole responsibility for addressing the problem. It's important to involve everyone who's interested' (Key informant). Such a multi-component effort must mobilize complementary media, institutional and interpersonal reinforcement in support of men. Mass media were highlighted as important potential channels of information about prostate cancer and screening, including radio and television stations and other commercial media targeting African American men. Local organizations were also named as viable channels, including local businesses (pubs and barbershops), health care institutions, insurance providers, churches, community groups, and fraternal organizations. Social and interpersonal channels, such as family and friends, were also identified.

Key informants pointed to the need to mobilize community leaders, survivors and family members (including females in men's lives) to expand community participation, provide interpersonal support, heighten knowledge about screening, increase community discussion about prostate cancer, and diminish cancer fear. They also recommended promotion of routine care-seeking as a norm among young people. Participants suggested promoting screening among professionals, men of means and community leaders to enhance leadership on the topic. 'The middle class can set the pace and talk about how "I had the test" to others. For example, the deacons of the church can tell members of the men's group that they were tested' (Key informant).

The two outreach programs evaluated sought to fill the gap in outreach about prostate cancer, and recruited survivors and peer educators to discuss prostate cancer with groups of men. The health educators in both programs provided information on prostate cancer statistics and disparities, risk factors, symptoms, screening and treatment. The process evaluations indicated that prostate cancer survivors, especially, were perceived as credible and compelling sources of information that groups of people could easily receive and understand. 'People know you and feel that you are telling the truth. They feel that they could talk more freely with us than with their physicians... They talked about it afterwards. People who don't normally talk about prostate cancer or the PSA would ask me questions' (Survivor educator). Survivor discussions got the full attention of participants, fostered sharing of information and stories from the participants and allowed the participants to ask questions during and after the discussions about prostate cancer symptoms, risk factors and treatment options. 'It reinforces the need for men to talk more openly about this problem' (Outreach session discussion participant).

Importantly, professional recommendations to promote informed decisionmaking about screening rather than screening itself were not adhered to. The potential side effects and disadvantages of screening were given limited attention in 
the outreach session discussions, as well as in the focus group discussions (FGDs). The topic was either talked about in passing or when one of the participants raised a specific, related question during the question and answer section. References to these points, if any, were made not as 'screening risks' but merely as another factor that acts as a barrier to screening (in the same vein as DRE stigma). Participant observers noted that none of the survivors who spoke chose to emphasize this issue. Similarly, informed decision-making was not mentioned in the discussions. These omissions suggest the difficulty for health educators of raising complicating issues in an already fraught topic, and the understandable preference to avoid them altogether. It is difficult to know whether this is because educators decide that the simpler message of 'Get screened' is more important, or because they are not fully briefed on the screening controversy.

Interview and focus group participants introduced specific recommendations related to actions health care institutions should take. Leading health care organizations need to engage in trust-building efforts with community organizations and leadership, including hiring more minority clinicians. Health services can also enhance services to minority populations by increasing their outreach, including offering free screening at convenient locations, thereby improving visibility in the community. Commenting on the inconvenience of health care, participants suggested creating coordinated care delivery services for men to facilitate care-seeking. 'Women have women's health clinics, but there is no men's clinic! Make it easier for them to seek care ... Help men maneuver through the system: like one-stop shopping' (Key informant).

Key informants and focus group participants suggested specific efforts to target individual behavior including raising awareness about prostate cancer and screening, given low levels of knowledge. In particular, they were enthusiastic about promoting the PSA, given the common aversion to the DRE.

Participants also advocated addressing DRE stigma by promoting the importance of having a consistent primary care provider. 'If men are in the system they will get care, but if they are healthy, they won't seek care and get tested' (Key informant). Noting the general reluctance to talk about prostate cancer, participants emphasized the need to encourage declarations from community leaders and others endorsing prostate cancer care-seeking and supporting community conversation about prostate cancer to allay cancer fear.

Consistent with recommendations, the evaluated outreach programs sought to raise awareness about prostate cancer screening, and to increase the comfort of African American men in talking about prostate cancer. Interviews with discussion participants in the process evaluations indicated that the survivor-led discussions got their attention. Participants reported knowledge gained regarding prostate cancer and screening, and heightened intent to get screened. Participants reported having discussed the session content with family and friends following the sessions. The one weakness noted in the sessions was limited delivery of screening risk information, and limited attention to informed decision-making.

\section{Discussion}

Prostate cancer prevention and control remain a quandary, especially in the context of efforts to eliminate health disparities. A divergence persists between research and 
practice: despite inadequate scientific evidence of prostate cancer screening benefits, disparities in prostate cancer incidence and mortality produce demands from community health advocates for programs promoting screening. The findings from the studies presented in this paper shed new light on this tension, establishing a fresh understanding of the social and institutional dynamics that shape prostate cancer prevention and control efforts, and offering new insights and strategies for intervention.

Many of the findings presented here reinforce the main concerns that are reflected in prior research: low levels of knowledge about prostate cancer and screening among African American men; lower likelihood of screening practice among men with lower incomes and levels of education; concerns about access to and discriminatory practice in health services and distrust of health services by African American men. New insights regarding social and institutional factors affecting prostate cancer care-seeking emerged: reluctance to talk about cancer, lack of routine preventive care, and stigma associated with DRE.

Our qualitative findings illuminate programmatic issues and research gaps related to prostate cancer prevention efforts. Our study points to the difficulties of adequately and accurately conveying risks of screening and promoting appropriate decision-making. The efforts to get men screened were concerted in the programs we evaluated, and the shortfall in terms of education about screening interpretation and decision-making was clear. Just how to address such a shortfall is not clear from our evidence, but it begs for more research about how screening risks and informed decision-making protocols can be integrated into community education programs (in contrast to clinical settings) (Meissner et al. 2004). Two strategies may facilitate this effort: reframing prostate cancer decision-making and survivor leadership.

Encouraging and facilitating community groups' promotion of informed decision-making is clearly part of the challenge. 'Get screened' is arguably a more straightforward and actionable message than 'Talk to your doctor about screening', and appears to be preferred by our community partners. One strategy to reframe decision making for community organizations is to reconceptualize screening decision-making as more than a single-event decision. A man considering whether or not to get screened for prostate cancer may face a number of more difficult subsequent decisions should he find that he has a high result on his PSA test. Some of these decisions include how to proceed with a diagnostic process, and whether and how to treat a cancer should it be diagnosed. We argue that such a suite of decisions should not be considered independently, but together. Organizations offering prostate cancer screening may best serve their clients by establishing an informational basis and facilitating support structures for the set of decisions (and relevant services).

Another approach is to couch informed decisions as an empowerment strategy in prostate cancer prevention programs, in order to tackle the persistent issue of distrust. Promoting informed decisions adds the informational burden of communicating about risks and uncertainty, but introduces the benefits of independent choice. Such a position joins informed decision principles with institutional strategies aiming to shift structural determinants that contribute to disparities. Community groups may find this rationale more convincing than the clinical argument that currently underlies informed decision recommendations. Health care providers and community members need to partner in crafting a message that is both true and 
accessible: 'Screening is important, and screening gives you choices. Know what your choices are'.

Finally, our research suggests that survivors can play an integral role in promoting conversations about prostate cancer. Discussion participants reported that survivor educators' insights struck a chord with them, and that they could relate to survivors' stories. Recent reports have suggested that survivors can successfully mobilize cancer education program participation by being the main source of initial information, and can enhance programs with their ability to share stories. Through face-to-face interactions with healthy men, prostate cancer survivor role models normalize the cancer experience, and alleviate the fear that cancer is a death sentence, or that it leads to social isolation. Involvement by prostate cancer survivors in the process of designing intervention content has proven productive in increasing knowledge and self-efficacy levels among participants. The word 'survivor' itself is perceived as positive - a perception that can only facilitate the internalizing of survivor educators' optimistic attitude and affirmative advice (Harwood and Sparks 2003). The present study establishes these claims about the potential of survivors as powerful health educators and makes a case for their increased involvement in health communication interventions.

While some may be concerned about survivors simply advocating screening, we argue instead that visible survivor leadership and testimony may enhance the decision-making protocol in several ways. First, survivors may have even greater credibility as sources of information than clinicians, and may substantively change men's minds about screening. Second, as survivors, they embody the idea that prostate cancer need not be a death sentence, undercutting cancer fear that can dissuade men from talking about and taking preventive action. Third, survivors' experience with the side effects of treatment may make them important allies to men seeking to understand and make sound decisions for themselves about screening, diagnosis and treatment.

Previous studies have documented the role of survivors in outreach in the case of other kinds of cancers, notably, breast cancer (Bailey et al. 2000, Williams-Brown et al. 2002, Hurd et al. 2003, Hansen et al. 2005, Bluthenthal et al. 2006). Yet the nature of survivors' contributions to knowledge and decision-making about prostate cancer screening, diagnosis and treatment is little known. Although survivors have been incorporated into cancer outreach programs for years (e.g., the American Cancer Society's Reach to Recovery program started in 1952) (Rogers et al. 1985), the examination of their precise impact and strengths has not been documented. In particular, there is a need to assess how survivors' experience with screening, diagnostic and treatment decisions may inform community-based decision support programs. In addition, programmatic support of survivors in prostate cancer outreach to date is ad hoc. Further research is required to better understand how to systematically support and promote survivors' experience in an educational setting, for maximum impact, at reasonable cost.

The community perspective reported here suggests that the survivor-led strategy will be most effective when it is implemented within a comprehensive prostate cancer control program. Such a program would include a collaboration of communitybased and local media, community and faith-based groups, and the health care industry. Informed by a coherent and consistent message strategy, survivor-led 
educational outreach may best produce routine care-seeking and a complete understanding of prostate cancer care issues among African American men.

These recommendations also highlight important questions for research. How can we best promote an informed decision-making process about prostate cancer screening, diagnosis and treatment in community-based educational outreach programs? What are survivors' contributions to knowledge and decision-making about prostate cancer screening, diagnosis and treatment? What role do social norms and interactions play in prostate cancer decisions?

Purposive and non-representative samples in each study limit the generalizability of the findings. The process evaluations addressed a limited number of outcome measures, and involved no comparison groups. However, the qualitative data provided in-depth insights into the phenomena under consideration, and allowed unexpected themes to emerge. Broad community participation enhanced the richness of our findings. The key informants represented multiple sectors in the community, and the focus group and discussion participants spanned a range of ages, social classes and educational levels. Multiple methods used in the needs assessment and process evaluations provided complementary streams of data enabling triangulation. While the studies did not always overlap in providing findings on specific themes, results across findings were consistent, enhancing our confidence in the results.

This set of studies reflects the diversity of communities in the African American population, and the obstacles that fundamentally influence access to quality health care. Both media and institutional outreach need to be designed systematically to reach the variety of networks, neighborhoods and cohorts that African Americans comprise. Men of testing age need informational, social and clinical support to make informed decisions. Young people need to be helped to recognize early the importance of a regular health care provider they trust and can talk to, so that when the time comes, trust is not a barrier. Influential members in a community, who have previously undergone the experience of screening and treatment, must be encouraged to lead the way by sharing their stories within their social networks. Knowledge is important and needed for all, and social norms will continue to shift with thoughtful and concerted effort. However, good communication cannot make up for service deficits. Accurate knowledge and supportive norms notwithstanding, the institutional barriers for poorer, less well-educated and less well-connected men are substantial and will require additional policy solutions.

\section{Acknowledgements}

The St. Louis Men's Group Against Cancer, the Saint Louis University Cancer Center, the Illinois Department of Health Center for Minority Services, and the Missouri Department of Health and Senior Services (\#U55/CCU721904-02) supported this original research. The study team is grateful to our community collaborators for providing facilities for group discussions and interviews and for facilitating recruitment of study participants. The many men and women who took part as key informants and discussion participants gave willingly of their time and provided insights; we are hopeful that we have adequately represented their collective wisdom. We are also grateful to our university colleagues for their critique and review of our research along the way; we take responsibility for any errors in the presentation. 


\section{References}

Abernethy, A., et al., 2005. Recruiting African American men for cancer screening studies: applying a culturally based model. Health Education \& Behavior, 32 (4), 441-451.

Agho, A. and Lewis, M., 2001. Correlates of actual and perceived knowledge of prostate cancer among African Americans. Cancer Nursing, 24 (3), 165-171.

American Cancer Society, 2006. Cancer facts \& figures 2006. Atlanta, GA: American Cancer Society.

American Cancer Society, 2007. Cancer facts \& figures 2007. Atlanta, GA: American Cancer Society.

American Cancer Society, 2008. Cancer facts \& figures 2008. Atlanta, GA: American Cancer Society.

Ashford, A., et al., 2001. Prostate carcinoma knowledge, attitudes, and screening behavior among African-American men in Central Harlem, New York City. Cancer, 91 (1), 164-172.

Bailey, E., Erwin, D., and Belin, P., 2000. Using cultural beliefs and patterns to improve mammography utilization among African-American women: the witness project. Journal of the National Medical Association, 92 (3), 136-142.

Barry, M., 2001. Prostate-specific-antigen testing for early diagnosis of prostate cancer. New England Journal of Medicine, 344 (18), 1373-1377.

Bluthenthal, R., et al., 2006. Witness for wellness: preliminary findings from a communityacademic participatory research mental health initiative. Ethnicity \& Disease, 16 (Suppl. 1), S1-18-S11-34.

Brawley, O., 1997. Prostate carcinoma incidence and patient mortality: the effects of screening and early detection. Cancer, 80 (9), 1857-1863.

Centers for Disease Control and Prevention, 2006. Behavioral risk factor surveillance system survey data. Atlanta, GA: US Department of Health and Human Services, Centers for Disease Control and Prevention.

Chan, E., 2001. Promoting informed decision making about prostate cancer screening. Comprehensive Therapy, 27 (3), 195-201.

Chu, K., Tarone, R., and Freeman, H., 2003. Trends in prostate cancer mortality among black men and white men in the United States. Cancer, 97 (6), 1507-1516.

Deadman, J., et al., 2001. Taking responsibility for cancer treatment. Social Science and Medicine, 53 (5), 669-677.

Demark-Wahnefried, W., et al., 1995. Knowledge, beliefs, and prior screening behavior among blacks and whites reporting for prostate cancer screening. Urology, 46 (3), 346-351.

deVere White, R., et al., 1998. Racial differences in clinically localized prostate cancers of black and white men. Journal of Urology, 159 (6), 1979-1982.

Dressler, W., 1993. Health in the African American community: accounting for health inequalities. Medical Anthropology Quarterly, 7 (4), 325-345.

Ferrini, R. and Woolf, S.H., 1998. American college of preventive medicine practice policy: screening for prostate cancer in American men. American Journal of Preventive Medicine, 15 (1), 81-84.

Fowke, J., et al., 2005. Prostate cancer screening between low-income African-American and Caucasian men. Urologic Oncology: Seminars and Original Investigations, 23 (5), 333-340.

Gamble, V., 1993. A legacy of distrust: African Americans and medical research. American Journal of Preventive Medicine, 9 (Suppl. 6), 35-38.

Gilligan, T., et al., 2004. Racial differences in screening for prostate cancer in the elderly. Archives of Internal Medicine, 164 (17), 1858-1864.

Hansen, L., et al., 2005. An educational program to increase cervical and breast cancer screening in Hispanic women: a southwest oncology group study. Cancer Nursing, 28 (1), 47-53.

Harwood, J. and Sparks, L., 2003. Social identity and health: an intergroup communication approach to cancer. Health Communication, 15 (2), 145-159. 
Hewitson, P. and Austoker, J., 2005. Part 2: patient information, informed decision-making and the psycho-social impact of prostate-specific antigen testing. BJU International, 95 (Suppl. 3), 16-32.

Hurd, T., et al., 2003. An evaluation of the integration of non-traditional learning tools into a community based breast and cervical cancer education program: The Witness Project of Buffalo. BMC Cancer, 3 (1), 18-25.

Kressin, N., et al., 2002. Racial differences in health-related beliefs, attitudes, and experiences of VA cardiac patients: scale development and application. Medical Care, 40 (Suppl. 1), I72I85.

Meissner, H., et al., 2004. Promoting cancer screening: learning from experience. Cancer, 101 (Suppl. 5), 1107-1117.

Miles, M. and Huberman, A., 1994. Qualitative data analysis: an expanded sourcebook. 2nd ed. Thousand Oaks, CA: Sage.

Myers, R., et al., 2000. African-American men and intention to adhere to recommended follow-up for an abnormal prostate cancer early detection examination result. Urology, 55 (5), 716-720.

National Cancer Institute, 2007. Prostate cancer screening. Available from: http://www.cancer. gov/cancertopics/pdq/screening/prostate/Patient/ [Accessed 5 December 2007].

Partin, M., et al., 2004. Randomized trial examining the effect of two prostate cancer screening educational interventions on patient knowledge, preferences, and behaviors. Journal of General Internal Medicine, 19 (8), 835-842.

Powell, I., et al., 1997. Outcome of African American men screened for prostate cancer: the Detroit education and early detection study. Journal of Urology, 158, 146-149.

Ries, L., et al., eds, 2000. SEER cancer statistics review, 1973-1997. Bethesda, MD: National Cancer Institute.

Rogers, T., Bauman, L., and Metzger, L., 1985. An assessment of the reach to recovery program. CA - A Cancer Journal of Clinicians, 35 (2), 116-124.

Shavers, V. and Brown, M., 2002. Racial and ethnic disparities in the receipt of cancer treatment. Journal of the National Cancer Institute, 94 (5), 334-357.

Steele, C., et al., 2000. Knowledge, attitudes, and screening practices among older men regarding prostate cancer. American Journal of Public Health, 90 (10), 1595-1600.

Stokols, D., 1992. Establishing and maintaining healthy environments: toward a social ecology of health promotion. American Psychologist, 47, 6-22.

Tingen, M., et al., 1998. Perceived benefits: a predictor of participation in prostate cancer screening. Cancer Nursing, 21 (5), 349-357.

US Preventive Services Task Force, 1996. Screening for prostate cancer. Guide to clinical preventive services. Washington, DC: US Department of Health and Human Services, Office of Disease Prevention and Health Promotion.

Volk, R., Cass, A., and Spann, S., 1999. A randomized controlled trial of shared decision making for prostate cancer screening. Archives of Family Medicine, 8 (4), 333-340.

Ward, E., et al., 2004. Cancer disparities by race/ethnicity and socioeconomic status. $C A$ : A Cancer Journal for Clinicians, 54 (2), 78-93.

Weinrich, S., et al., 1998a. Recruitment of African Americans into prostate cancer screening. Cancer Practice, 6 (1), 23-30.

Weinrich, S., et al., 1998b. Increasing prostate cancer screening in African American men with peer-educator and client-navigator interventions. Journal of Cancer Education, 13 (4), 213219.

Williams-Brown, S., Baldwin, D., and Bakos, A., 2002. Storytelling as a method to teach African American women breast health information. Journal of Cancer Education, 17 (4), 227-230.

Wong, Y., et al., 2006. Survival associated with treatment vs observation of localized prostate cancer in elderly men. Journal of the American Medical Association, 296 (22), 2683-2693. 
Copyright of Ethnicity \& Health is the property of Routledge and its content may not be copied or emailed to multiple sites or posted to a listserv without the copyright holder's express written permission. However, users may print, download, or email articles for individual use. 